Clinical Article

\title{
Solitaire AB Stent-Assisted Coiling of Wide-Neck Micro Aneurysms
}

\author{
Xue-dong Li, M.D., ' Jun Qin, M.D., ${ }^{*}$ Zhen-yong Xiao, M.D., Yi Feng, M.D., Jia-kang Chen, M.D. \\ Department of Neurosurgery, Liuzhou Workers' Hospital, Guangxi, PR China
}

\begin{abstract}
Objective : Solitaire AB stent-assisted coiling facilitates the endovascular treatment of wide-necked intracranial aneurysms. We present our experience of coiling the micro-aneurysms of wide-neck with Solitaire AB stent assisting in a single center.

Methods : Thirty-one Solitaire AB stents were used to treat via endovascular approach patients with 31 wide-neck micro aneurysms in a single center in China. Technical and clinical complications were recorded. Modified Rankin Scale was used to evaluate the patients' conditions via clinic and telephone follow-up.

Results : The mean width of aneurysm sac was $2.30 \pm 0.42 \mathrm{~mm}$, and the mean diameter of aneurysm neck was $2.83 \pm 0.48 \mathrm{~mm}$. Complete occlusion was achieved in 28 aneurysms (90.32\%); neck remnant was seen in 3 aneurysms (9.68\%). Technical and clinical complications related to the procedure were encountered in four patients (12.5\%). Two patients died (6.25\%). No patient had a permanent deficit.

Conclusion : Solitaire AB stent was a safe and efficiency tool in assisting coiling of micro aneurysms with wide neck, but may be not suitable for a blaster-like one. Mid- and long-term follow-up will be required to elucidate the impact of the Solitaire AB stent on recanalization rate.
\end{abstract}

Key Words : Coiling $\cdot$ Micro aneurysm $\cdot$ Stenting $\cdot$ Wide-neck.

\section{INTRODUCTION}

A micro-aneurysm with wide-neck is defined as an aneurysm small than $3 \mathrm{~mm}$ whose longitude size was equal or larger than width of neck, which was often seen in Asian population ${ }^{6,25,26)}$. Microsurgical clipping with or without its parent artery sacrificed was the usual way to treat it ${ }^{18)}$. As the development of endovascular treatment and instruction of Solitaire AB stent, stent assisted coiling provides a new chance for these aneurysms with parent arteries preserved ${ }^{7,20,23)}$. We presented here a study of 31 wide-neck micro-aneurysms treated by Solitaire $\mathrm{AB}$ stent assisted coiling in a single-center.

\section{MATERIALS AND METHODS}

Our study including 31 patients with 31 wide-neck micro aneurysms treated with an electrical detachable self-expandable Solitaire AB stent (ev3 Neurovascular, Irvine, CA, USA) was conducted between 2010 to 2014 in our hospital. Patients harboring intracranial aneurysms, ruptured or un-ruptured, arising from a parent vessel with a diameter $\leq 3.0 \mathrm{~mm}$ and presenting wideneck or dome-to-neck ratio of $<1$ were included. Exclusion factors included fusiform and dissecting aneurysms, and aneurysms associated with an arteriovenous malformation were also excluded.

\section{Patients}

Thirty-one patients (14 males and 17 females; age range 3869 years; mean age : $53.35 \pm 7.57$ years) harboring 31 aneurysms were included in our study. 27 of the patients were admitted in with subarachnoid hemorrhage (SAH), and 4 were discovered by accident. Hunt-Hess grade scale was I in 11 patients, grade II in 11 patients, grade III in 7 patients, and grade IV in 2 patients.

\section{Aneurysms}

A total of 31 aneurysms were treated via an endovascular approach. Most aneurysms (96.77\%) were located in the internal carotid system. Carotid-posterior communicating segment represented the most frequent location (51.61\%). Location and measurements are summarized in Table 1, 2, respectively.

• Received : July 9, 2015 • Revised : July 9, 2015 • Accepted : November 26, 2015

$*$ These authors contributed equally to this work.

- Address for reprints : Jia-kang Chen, M.D.

Department of Neurosurgery, Liuzhou Workers' Hospital, 1st Liushi Road, Yufeng District, Liuzhou, Guangxi, PR China

Tel : +86-0772-3815284, Fax : +86-0772-381258, E-mail : CJKDOCTORLGY@163.com

- This is an Open Access article distributed under the terms of the Creative Commons Attribution Non-Commercial License (http://creativecommons.org/licenses/by-nc/3.0) which permits unrestricted non-commercial use, distribution, and reproduction in any medium, provided the original work is properly cited. 


\section{Procedure}

Endovascular procedures were performed under general anesthesia and systemic heparinization. The Solitaire AB stent size and length were determined by the operator according to the diameter of the vessel and the length of the neck. The stent is deployed within the parent vessel at the site of the intracranial aneurysm across the wide-necked aneurysm. In most of the cases, the aneurysm was treated by a combination of stenting and coiling using either the half-release technique or by stent placement followed by micro-catheter placement in the sac through the stent struts. No stent was retrieved after the procedure.

\section{Antiplatelet regimen}

Antiplatelet medications were various according to the operation itself. The antiplatelet medications regimen of patients underwent elective operations was differing from those undertook emergence ones. Our Antiplatelet medication protocol was summarized in Table 3.

\section{Data analysis}

Permanent morbidity and mortality of endovascular treatment (EVT) were evaluated before and after treatment, at hospital

Table 1. Aneurysm location

\begin{tabular}{lc}
\hline \multicolumn{1}{c}{ Aneurysm location } & No. of patient (\%) \\
\hline Internal Carotid system & $30(96.77)$ \\
Anterior communicating artery & $3(9.68)$ \\
Posterior communicating artery & $16(51.61)$ \\
Carotid-anterior choroidal artery & $1(3.23)$ \\
Middle cerebral artery & $2(6.45)$ \\
Carotid-ophthalmic artery & $8(25.81)$ \\
Vertebral basilar system & $1(3.23)$ \\
Posterior cerebral artery & $1(3.23)$ \\
\hline This table showed the clinical condition of the aneurysms. We had 30 aneurysms \\
of internal carotid system, and only one of the vertebral basilar system
\end{tabular}

Table 2. Aneurysm measurements

\begin{tabular}{lc}
\hline \multicolumn{1}{c}{ Size of aneurysm } & Mean \pm SD $(95 \% \mathrm{CI})(\mathrm{mm})$ \\
\hline Dome width & $2.30 \pm 0.42$ \\
Neck width & $2.83 \pm 0.48$ \\
Dome-to-neck ratio & $0.82 \pm 0.10$ \\
\hline
\end{tabular}

The sizes of the aneurysms were listed above. They were all wide-neck microaneurysms discharge, and at 1-month and 6-month follow-up. Morbidity was defined as a modified Rankin Scale (mRS) score of 2 to 5 . When preoperative $\mathrm{mRS}$ was greater than 1 and morbidity was defined by any increase of $\mathrm{mRS}$, any modification within 30 days after EVT was designated as treatment-related. Any death within 30 days of endovascular treatment was designated a treatment-related death.

Senior doctors of both neurosurgery and neuro-imaging departments were asked to evaluate the degree of aneurysmal occlusion, which was defined as three conditions : complete occlusion, neck remnant, and aneurysm remnant. It was defined by using the simplified three-point Jean Raymond classification scale : complete occlusion, neck remnant, and aneurysm remnant ${ }^{5}$.

\section{RESULTS}

\section{Technical results}

A total of 31 Solitaire AB stents were used to treat 31 patients with 31 micro-wide-neck aneurysms. All of the stents were implanted, including 15 stents $4 \times 15 \mathrm{~mm}, 11$ stents $4 \times 20 \mathrm{~mm}$, and 5 stents $6 \times 20 \mathrm{~mm}$. No stent was retrieved. So, our rate of successful stent delivery was 100\%. During our surgical procedure, stable stent placement with complete coverage across the aneurysm neck with parent artery patency was achieved in all aneurysms.

\section{Anatomic results}

According the analysis of our neuroimaging department, postprocedural aneurysmal occlusions were the following: complete occlusion, 28 aneurysms (90.32\%); neck remnant, 3 aneurysms (9.68\%), including two were $95 \%$ occluded and 1 were $90 \%$ occluded.

\section{Complications}

Two aneurysms ruptured during our procedure, which were all occluded completely and rapidly. Two patients underwent an acute embolism event inner stent, which were treated by 500 thousand units of urokinase via a direct intra-catheter injection, and the embolisms were solved, causing no harm. Two patients deceased in our study. One underwent a recurrence of SAH with coils escaped from the aneurysm after EVT due to re-rupturing of the aneurysm, causing an untreatable intracranial hematoma, which led to her death. And the other one, who had a chronic

Table 3. Summary of the antiplatelet medications

\begin{tabular}{llc}
\hline Timing & \multicolumn{1}{c}{ Elective operation (unruptured aneurysms) } & Emergency operation (ruptured aneurysms) \\
\hline Before EVT & $\begin{array}{c}\text { Clopidogrel } 75 \mathrm{mg} / \mathrm{d} \text { \& aspirin } 300 \mathrm{mg} / \mathrm{d} \text { by oral } \\
\text { (3 days before EVT) }\end{array}$ & $\begin{array}{c}\text { Clopidogrel } 75 \mathrm{mg} \& \text { aspirin } 300 \mathrm{mg} \text { by oral }(4 \mathrm{~h} \text { before EVT) } \\
\text { OR }\end{array}$ \\
During EVT & $\begin{array}{c}\text { Heparin } 3000 \mathrm{u} \text { (first hour) \& } 1000 \mathrm{u} / \mathrm{h} \text { afterward intravenous } \\
\text { Tirofiban } 10 \mathrm{ug} / \mathrm{kg} \cdot \mathrm{min} \times 3 \mathrm{~min}+1 \mathrm{ug} / \mathrm{kg} \cdot \mathrm{min} \text { intravenous }\end{array}$ \\
After EVT & $\begin{array}{c}\text { Low molecular heparin } 4000 \mathrm{u} \mathrm{IH}, \mathrm{Q} 12 \mathrm{~h} \times 2 \text { days; clopidogrel } 75 \mathrm{mg} / \mathrm{d} \text { \& aspirin } 100 \mathrm{mg} / \mathrm{d} \text { by oral.; lasting for } 3 \mathrm{months} \mathrm{from} \mathrm{the} \\
\text { first day after EVT; \& single aspirin } 100 \mathrm{mg} / \mathrm{d} \text { by oral, lasting for } 3 \mathrm{months}\end{array}$ \\
\hline
\end{tabular}

This table showed our antiplatelet medications periprocedure 
rental failure before admitting, suffered an acute renal failure after EVT, leading to her death. The other patients were treated well with no treatment related permanent complication. In addition, no hematoma related with antiplatelet medication was reported.

\section{Follow-up}

Follow-up study was carried out between 5 to 54 months (mean $25.69 \pm 12.57$ months). Patients were asked to have a CT angiography (CTA) or digital subtraction angiography (DSA) 6 months later after discharging. And clinic and telephone follow-up was suitable for those who discharged for 1 year or more. In our study, except for two patients died in para-procedure, others recovered well. The mRS scores improved as time goes on. Our total morbidity was low (6.45\%).

\section{DISCUSSION}

The introduction of stents offered new choices in treating wide-neck micro aneurysms ${ }^{21}$. However, early stents had various limiting, such as not soft enough, hard to deploy, inability to retrievable, and poor visibility. The Solitaire AB stent is fully retrievable and soft enough to be deployed to achieve ideal coverage of the neck ${ }^{7}$.

\section{Safety and efficiency of the Solitaire AB stent}

Solitaire AB stent system was approved as a safe stent assisting coiling, which had less related complications compared with Neuroform (Stryker Neurovascular, Fremont, CA, USA) and Enterprise (Cordis Neurovascular/Johnson \& Johnson, Miami Lakes, FL, USA) stents ${ }^{2,4,5,17)}$. In our study, we found Solitaire AB stent was easy to be pushed out of the catheter and deployed. Moreover, it could be retrieved when the coverage of aneurysm neck was not satisfied. Our study confirms a high success rate; similar to a previous single-center retrospective study by Clajus et al. $^{3)}$. Compared with other series using Solitaire stent, our overall periprocedural complication rate is high (12.5\%), which was similar to the short time result of the Solitaire Aneurysm Remodeling study ${ }^{5}$, while there was no device-related permanent morbidity. These results could be explained by the result that 27 cases of 31 patients $(87.10 \%)$ presented with an acute SAH, 9 of who were beyond Grade III (Hunt-Hess grade scale). In our study, no stent was retrieved after the procedure. We made our decisions based on the stability of the coils and the status of parent artery. Further study is required to better elucidate the safety profile of stent-assisted coiling in the setting of acute SAH. In our study, all the patients were asked to have a DSA or CTA study six-month later after discharge, and no re-bleeding, aneurysm recurrence or stent-related ischemia was found. The Solitaire $\mathrm{AB}$ stent was safe in assisting coiling the micro-aneurysm with wide neck.

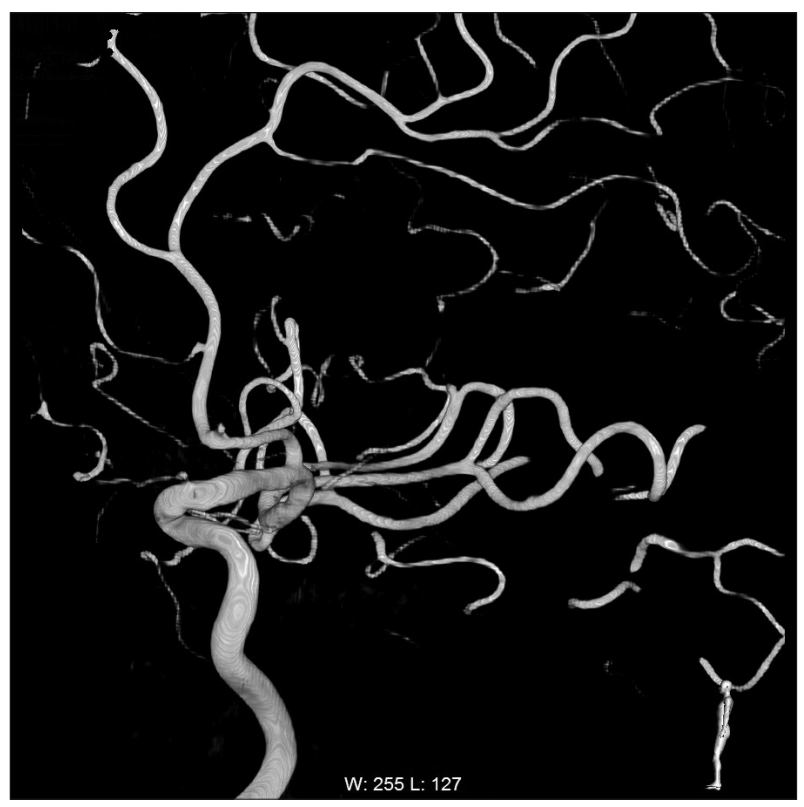

Fig. 1. The 3D DSA showed a blood blister-like aneurysm in internal carotid artery.

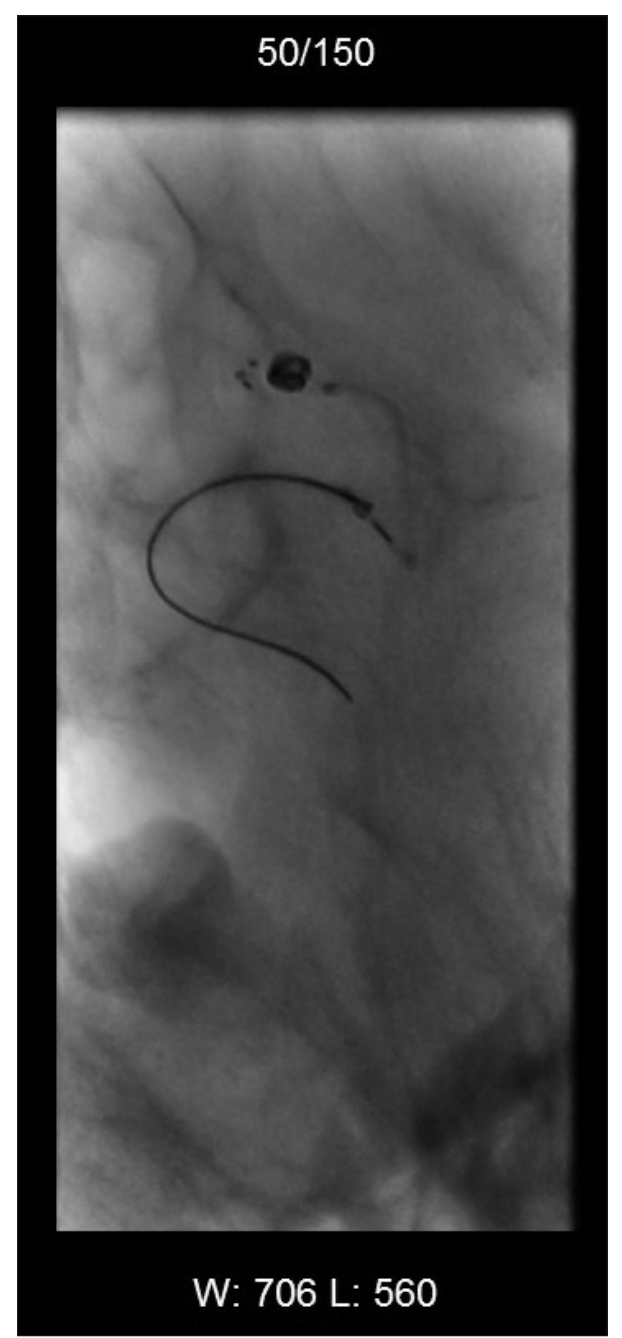

Fig. 2. Only one coil was planted in a really hard way. 


\section{Is a blood blaster-like aneurysm should be treated via endovascular?}

One of our patients underwent a post-procedural recurrent $\mathrm{SAH}$ with coils escaped that had a poor result at the end. We conjectured that it might be a blood blister-like aneurysm, which seemed as a wide-neck micro-aneurysm on DSA image, which was really more dangerous than a normal micro-aneurysm (Fig. $1,2)$. Only one coil was planted by really hard attempts and unfortunately the aneurysm re-ruptured. The Fig. 3 showed the CT scan admitted, and the Fig. 4 showed the CT scan after surgery. The treatment of a blood blaster-like aneurysm was various $^{22)}$. Surgical clipping with or without parent artery preserved was first used to treat such lesion. Neurosurgical clipping of blister-like aneurysms should be reserved for aneurysms of the anterior ICA segment in which endovascular strategies are not

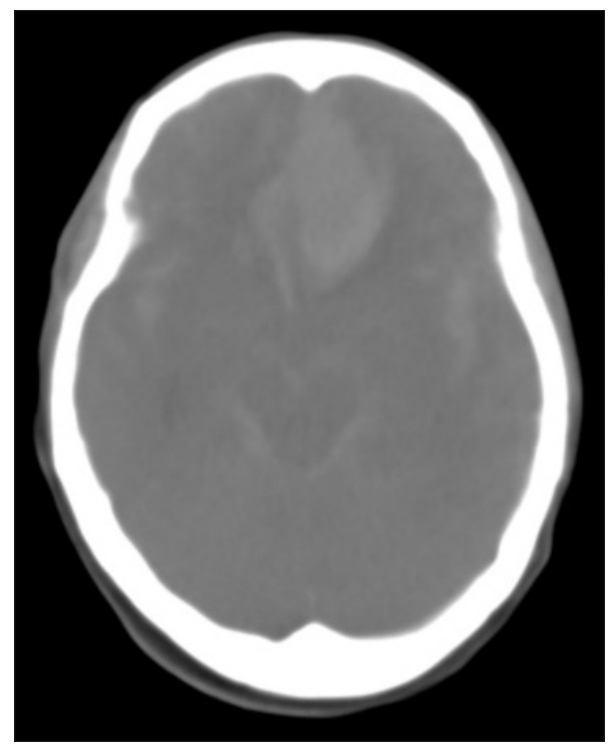

Fig. 3. The CT scan when admitted.

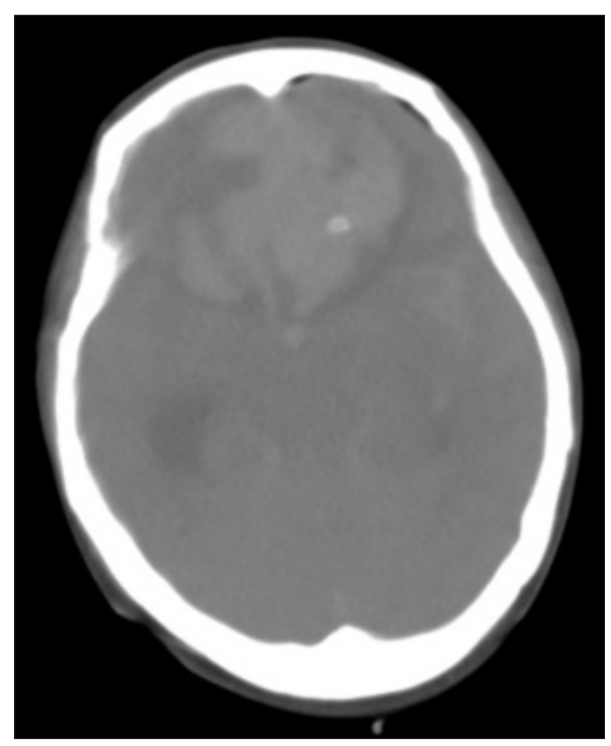

Fig. 4. The CT scan when it re-ruptured. practicable for technical reasons or neuroradiological experiences are not available ${ }^{22)}$. EVT, including coiling with or without stent, covered stents technique and flow diverter was used to treat it in nowadays. Endovascular procedures with stent-assisted coiling have been reported to be successful but still remain dangerous due to the high risk of aneurysm perforation by the coils ${ }^{1,11,13,15,16,19)}$. At present, covered stents and flow diverters seem to be most promising techniques to stabilize the arterial wall and to minimize the procedural trauma of the fragile aneurysm itself. For those complex ones, wrapping or trapping was the "second best" choice. Sometimes, revascularization techniques were useful for some special cases ${ }^{8-10,24)}$. Blister-like aneurysms are small, thin-walled, and broad-based bulges, of which; neuro-radiological imaging will not be conclusive. It is too fragile to directly clip or coil. Endovascular stenting technique, which avoids direct operating on aneurysm itself, is seemed as the preferred treatment in dealing with the aneurysms. Trapping and bypass techniques are the more challenging surgical attempts carrying the risk of cerebral ischemia.

\section{Size of a single cell of the solitaire $A B$}

According to a comparison study of functional and physical properties of self-expanding intracranial stents [Neuroform3, Wingspan, Solitaire, Leo (+), Enterprise $]^{14)}$, Solitaire AB stent is a closed-cell design, self-expanding stent for intracranial vessels, which has the largest cell size-about $2-3 \mathrm{~mm}$. As observed by other sites, the thrombogenicity of the Solitaire stent is low and allows deployment with heparinization and aspirin induced antiaggregation only, without the administration of clopidogrel ${ }^{12)}$. This is a major advantage in the treatment of patients with recently ruptured aneurysms. An intrinsic hemodynamic effect of the Solitaire is apparently non-existing, mainly due to the large cell size ${ }^{14)}$. Larger cells are easier accessible for a microcatheter but have less hemodynamic effect on the aneurysm's in- and outflows. In addition, large cells made protecting the adjacent branches during treatment possible. In our study, no branch-related ischemia happened during periprocedure. However, there were some difficulties in dealing with the large cell stent, to overcome that, we got some progress. We used some large size stents (diameter $>6 \mathrm{~mm}$ ) in some cases. When the stent was delivered and deployed, a large size stent could be opened partly, which made part of the stent wall overlapped, in that case, the cell became "small". In some conditions, we used a long coil, allowing a coil tail was just between the cell and the aneurysm, which made the cell "small", too. The large cells can be the advantage when we use the stent in right way; otherwise, they are troubles we should solve.

\section{CONCLUSION}

We here presented our experience of coiling wide-neck micro aneurysms with stent assisted in a single center in China. Solitaire $\mathrm{AB}$ stent was convenient in deploying when covering the 
aneurysm, and our short-time follow up showed a low recurrence and a good prognosis which suggested that Solitaire $A B$ stent was a safe and efficiency tool in assisting coiling of micro aneurysms with wide neck. For the aneurysm looked like a blister-like one, a single stent or double stents without coiling might be a good choice. However, the long-time safety and efficiency of Solitaire Stent were subject to observation.

\section{References}

1. Ahn JY, Cho JH, Jung JY, Lee BH, Yoon PH : Blister-like aneurysms of the supraclinoid internal carotid artery : challenging endovascular treatment with stent-assisted coiling. J Clin Neurosci 15 : 1058-1061, 2008

2. Biondi A, Janardhan V, Katz JM, Salvaggio K, Riina HA, Gobin YP : Neuroform stent-assisted coil embolization of wide-neck intracranial aneurysms : strategies in stent deployment and midterm follow-up. Neurosurgery 61 : 460-468; discussion 468-469, 2007

3. Clajus C, Sychra V, Strasilla C, Klisch J : Stent-assisted coil embolization of intracranial aneurysms using the Solitaire ${ }^{\mathrm{TM}} \mathrm{AB}$ Neurovascular Remodeling Device : initial and midterm follow-up results. Neuroradiology $55: 629-638,2013$

4. Gory B, Klisch J, Bonafé A, Mounayer C, Beaujeux R, Moret J, et al. : Solitaire $\mathrm{AB}$ stent-assisted coiling of wide-necked intracranial aneurysms : mid-term results from the SOLARE Study. Neurosurgery 75 : 215-219; discussion 219, 2014

5. Gory B, Klisch J, Bonafé A, Mounayer C, Beaujeux R, Moret J, et al. : Solitaire $\mathrm{AB}$ stent-assisted coiling of wide-necked intracranial aneurysms : short-term results from a prospective, consecutive, European multicentric study. Neuroradiology $55: 1373-1378,2013$

6. Gupta V, Chugh M, Jha AN, Walia BS, Vaishya S : Coil embolization of very small ( $2 \mathrm{~mm}$ or smaller) berry aneurysms : feasibility and technical issues. AJNR Am J Neuroradiol 30 : 308-314, 2009

7. Henkes H, Flesser A, Brew S, Miloslavski E, Doerfler A, Felber S, et al. : A novel microcatheter-delivered, highly-flexible and fully-retrievable stent, specifically designed for intracranial use. Technical note. Interv Neuroradiol 9: 391-393, 2003

8. Ishikawa T, Mutoh T, Nakayama N, Yasuda H, Nomura M, Kazumata K, et al. : Universal external carotid artery to proximal middle cerebral artery bypass with interposed radial artery graft prior to approaching ruptured blood blister-like aneurysm of the internal carotid artery. Neurol Med Chir (Tokyo) 49 : 553-558, 2009

9. Kamijo K, Matsui T : Acute extracranial-intracranial bypass using a radial artery graft along with trapping of a ruptured blood blister-like aneurysm of the internal carotid artery. Clinical article. J Neurosurg 113 : 781-785, 2010

10. Kawashima A, Okada Y, Kawamata T, Onda H, Kubo O, Hori T: Successful treatment of a blood blister-like aneurysm of the internal carotid artery by trapping with a high-flow bypass. J Clin Neurosci 15 : 797-800, 2008

11. Kim BM, Chung EC, Park SI, Choi CS, Won YS : Treatment of blood blister-like aneurysm of the internal carotid artery with stent-assisted coil embolization followed by stent-within-a-stent technique. Case report. J
Neurosurg $107:$ 1211-1213, 2007

12. Klisch J, Eger C, Sychra V, Strasilla C, Basche S, Weber J : Stent-assisted coil embolization of posterior circulation aneurysms using solitaire $\mathrm{ab}$ : preliminary experience. Neurosurgery 65 : 258-266; discussion 266, 2009

13. Korja M, Rautio R, Valtonen S, Haapanen A : Primary treatment of ruptured blood blister-like aneurysms with stent-assisted coil embolization : report of two cases. Acta Radiol 49 : 180-183, 2008

14. Krischek O, Miloslavski E, Fischer S, Shrivastava S, Henkes H : A comparison of functional and physical properties of self-expanding intracranial stents [Neuroform3, Wingspan, Solitaire, Leo+, Enterprise]. Minim Invasive Neurosurg $54: 21-28,2011$

15. Lee JW, Choi HG, Jung JY, Huh SK, Lee KC : Surgical strategies for ruptured blister-like aneurysms arising from the internal carotid artery : a clinical analysis of 18 consecutive patients. Acta Neurochir (Wien) 151 : 125-130, 2009

16. McNeely PD, Clarke DB, Baxter B, Vandorpe RA, Mendez I : Endovascular treatment of a "blister-like" aneurysm of the internal carotid artery. Can J Neurol Sci 27 : 247-250, 2000

17. Mocco J, Snyder KV, Albuquerque FC, Bendok BR, Alan SB, Carpenter JS, et al. : Treatment of intracranial aneurysms with the Enterprise stent : a multicenter registry. J Neurosurg 110:35-39, 2009

18. Molyneux A, Kerr R, Stratton I, Sandercock P, Clarke M, Shrimpton J, et al. : International Subarachnoid Aneurysm Trial (ISAT) of neurosurgical clipping versus endovascular coiling in 2143 patients with ruptured intracranial aneurysms : a randomised trial. Lancet $360: 1267-1274,2002$

19. Park JH, Park IS, Han DH, Kim SH, Oh CW, Kim JE, et al. : Endovascular treatment of blood blister-like aneurysms of the internal carotid artery. J Neurosurg 106 : 812-819, 2007

20. Pierot L, Spelle L, Vitry F; ATENA Investigators : Immediate clinical outcome of patients harboring unruptured intracranial aneurysms treated by endovascular approach : results of the ATENA study. Stroke 39 : 2497-2504, 2008

21. Piotin M, Blanc R, Spelle L, Mounayer C, Piantino R, Schmidt PJ, et al. : Stent-assisted coiling of intracranial aneurysms : clinical and angiographic results in 216 consecutive aneurysms. Stroke 41 : 110-115, 2010

22. Regelsberger J, Matschke J, Grzyska U, Ries T, Fiehler J, Köppen J, et al. : Blister-like aneurysms--a diagnostic and therapeutic challenge. Neurosurg Rev 34 : 409-416, 2011

23. Shapiro M, Becske T, Sahlein D, Babb J, Nelson PK : Stent-supported aneurysm coiling : a literature survey of treatment and follow-up. AJNR Am J Neuroradiol 33 : 159-163, 2012

24. Shimizu H, Matsumoto Y, Tominaga T : Non-saccular aneurysms of the supraclinoid internal carotid artery trunk causing subarachnoid hemorrhage : acute surgical treatments and review of literatures. Neurosurg Rev 33 : 205-216, 2010

25. van Rooij WJ, Keeren GJ, Peluso JP, Sluzewski M : Clinical and angiographic results of coiling of 196 very small $(<$ or $=3 \mathrm{~mm})$ intracranial aneurysms. AJNR Am J Neuroradiol 30 : 835-839, 2009

26. Wong GK, Teoh J, Chan EK, Ng SC, Poon WS : Intracranial aneurysm size responsible for spontaneous subarachnoid haemorrhage. Br J Neurosurg $27: 34-39,2013$ 